\title{
Changing provider behaviour to increase nurse visits for obesity in family practice: the 5 As Team randomized controlled trial
}

\author{
Denise L. Campbell-Scherer MD PhD, Jodie Asselin PhD, Adedayo M. Osunlana MBBS MPH, \\ Ayodele A. Ogunleye PhD, Sheri Fielding NP MS, Robin Anderson RD, Andrew Cave MBChB MClSc, \\ Jeffrey A. Johnson PhD, Arya M. Sharma MD
}

\section{Abstract}

Background: There is increasing recognition that health care professionals often fail to provide meaningful obesity care in routine clinical practice. There is scant information on how to support practice change. The objective of the 5AsT trial was to assess whether a co-created educational intervention would increase the quantity of obesity visits conducted by family practice nurses.

Methods: We conducted a randomized controlled trial with convergent mixed-methods evaluation in a primary care network in Alberta, Canada. The intervention, based on the Theoretical Domains Framework and 5As of Obesity Management, included 12 2-hour interactive educational sessions from November 2013 to April 2014. Twenty-four teams of nurses, mental health workers and dietitians were randomly assigned to receive the intervention or regular training. The primary outcome measure was the rate ratio of nurse visits for adult obesity care to total clinical visits. Qualitative thematic analysis was previously used to identify barriers and facilitators to intervention uptake. In this study, mixed-methods analysis assessed the impact of these factors on individual nurses' outcomes.

Results: There was no significant increase in visits over the 6-month intervention (rate ratio 1.30, 95\% confidence interval [Cl] 0.83-2.03) nor the 9-month post-intervention period (rate ratio $1.38,95 \% \mathrm{Cl} 0.87-2.19$ ). However, provider confidence, views of obesity management, role identity and team and patient relationships were found to affect individual nurses' uptake of the intervention.

Interpretation: Although the intervention did not demonstrate a significant increase in nurse visits for obesity care, this study provides insights into health care practitioners' challenges in changing their approach to obesity management. To improve provider capacity to change effectively within their teams, interventions need to foster not only provider knowledge but also confidence. Trial registration: ClinicalTrials.gov, no. NCT01967797.

besity and its chronic disease complications are surging worldwide, ${ }^{1,2}$ but health care professionals are poorly prepared to tackle the prevention and treatment of obesity in clinical practice; deficits in knowledge about the complexity of obesity and its management, as well as the need for team-based care, contribute. ${ }^{3}$ Evidence is sparse on how to change provider behaviour to improve obesity assessment and management in primary care. ${ }^{4-6} \mathrm{~A}$ suite of tools and resources to support primary care providers called the 5As of Obesity Management (the 5As: ask, assess, advise, agree, assist) has been developed in Canada. ${ }^{7-11}$ This approach emphasizes obesity as a chronic disease requiring long-term treatment, the importance of prevention, and assessment of root causes to better understand how psychosocial and medical comorbidities promote obesity. Use of the 5 As has been demonstrated to improve practitioners' efficacy in providing obesity counselling ${ }^{12-14}$ and patient weight loss. ${ }^{15}$
The 5As Team (5AsT) program was developed in collaboration with a large primary care network (PCN) in Alberta, Canada. Our overarching research question was whether a 6-month team-based learning collaborative with educational

Competing interests: Denise Campbell-Scherer was an unpaid board member for the Edmonton Southside Primary Care Network. Arya Sharma has received personal fees from Takeda for serving as a member of the data safety monitoring board for an anti-obesity trial, and he has received personal fees from Novo Nordisk for serving on the advisory board for an anti-obesity drug. Andrew Cave reports a grant from AstraZeneca for an asthma study. No other competing interests were declared.

This article has been peer reviewed.

Correspondence to: Denise Campbell-Scherer, denise.campbell-scherer@ualberta.ca

CMAJ Open 2019. DOI:10.9778/cmajo.20180165 
components developed to specifically address practitioners' perceived needs would be effective at changing their approach to obesity management. ${ }^{4}$ The specific objective of this randomized controlled trial (the 5AsT trial) was to assess whether this intervention would increase the quantity of visits conducted by chronic disease nurses working in family practice in which, by their own estimate, substantive conversations about obesity occurred with patients in their real-world practice settings. ${ }^{16,17}$

\section{Methods}

\section{Study design}

\section{Overview and setting}

The 5As'T trial was an allocation-concealed, blinded, pragmatic, randomized controlled trial with convergent mixedmethods evaluation (Figure 1). The pragmatic design, with use of existing primary care structures, minimal selection criteria, and tailoring of the intervention to the setting, investigated the real-world impact of the intervention.

The 5AsT trial was conducted in partnership with a large PCN in Alberta, Canada, the Edmonton Southside Primary Care Network. Health care in Alberta is universal and is funded by Alberta Health, which created and funds PCNs as not-for-profit corporations. The PCN corporation employs nonphysician multidisciplinary health care providers on salary, including the nurses, dietitians and mental health workers who participated in this study. The quantitative and mixed-methods portions of this study focus on the nurses, while the qualitative portions of the study focus on the nurses, dietitians and mental health workers.

The purpose of PCNs is to support evolution to teambased primary care in Alberta, particularly for chronic disease management. The PCN embeds the nurses, dietitians and mental health workers in member physicians' family practice clinics, in addition to providing centralized patient programming. Member physicians with private family practices voluntarily join the PCN; their private practice business is separate from the PCN. In this setting family physicians are predominantly fee for service, with the majority supporting their practices' operations via their clinical billings.

Our PCN partner was concerned that even though they had trained all of their employees on obesity management, they had observed that only dietitians were focusing on obesity in their consultations. The PCN clinical lead partnered with the research team to write the grant proposal and designated a clinical liaison to work with the team to develop and implement a 6-month (November 2013 to April 2014) teambased intervention to address this gap in care. ${ }^{16,18}$

\section{Intervention}

The 5AsT intervention was a 6-month team-based learning collaborative with educational components developed to specifically address practitioners' perceived needs. The 5As'T protocol and an intervention report created using the EQUATOR network's TIDieR guide have been published previously. ${ }^{16,17,19}$ The guide includes information on the

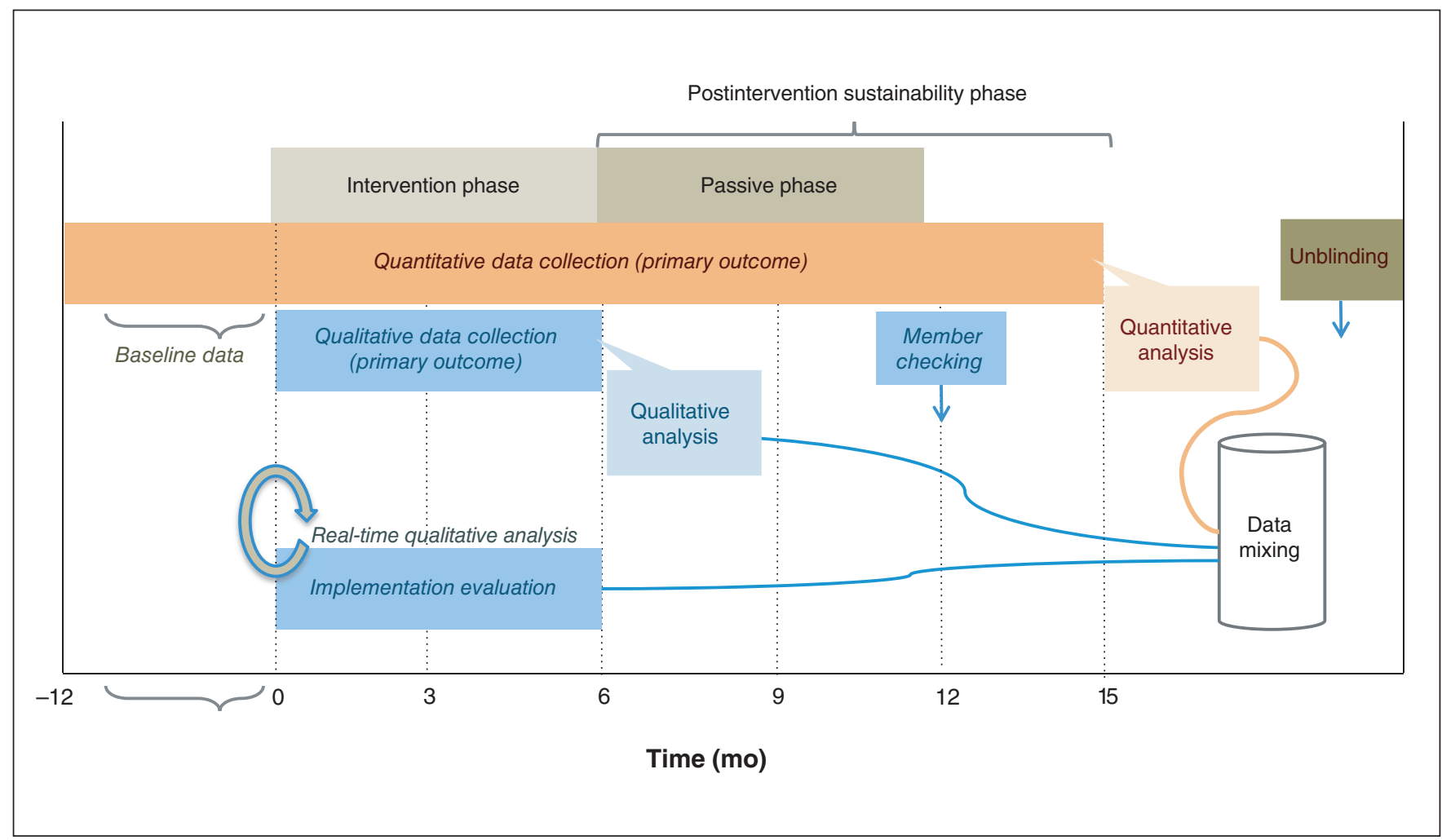

Figure 1: 5As Team study diagram. 
intervention design, theory, content, implementation and participant attendance/evaluation. In brief, the intervention consisted of 12 2-hour large-group interactive educational sessions delivered over 6 months. The intervention, which built upon the 5 As of Obesity Management and the Theoretical Domains Framework, was created in partnership with front-line providers on the basis of their self-assessed needs. ${ }^{20}$ Interactive sessions addressing diverse aspects of obesity management were supported by an internal clinical champion (a dietitian) and external content experts according to need. ${ }^{16}$ Sessions were followed by learning collaborative discussions in which interprofessional clinic teams consisting of nurses, dietitians and mental health workers shared their experiences with, and barriers to, implementing what they had learned and set goals for their practices. The intervention sessions, video links and tools are available online. ${ }^{21}$

All control and intervention participants received training in chronic disease management when they joined the PCN. This training included the Alberta Health Services Chronic Disease Management Training 1-day course $(7 \mathrm{~h})$ and the Edmonton Southside Primary Care Network's obesity training $(4 \mathrm{~h})$. In addition, intervention participants received the 6-month 5 AsT intervention described above.

\section{Participants and randomization}

Our partner PCN served 190724 patients on Apr. 1, 2013. At that time, 24 family practices serving 157470 patients had PCN interprofessional team support composed of registered nurses or nurse practitioners (nurses), registered dietitians and mental health workers. All of these allied health professionals were included in the study. All health care providers randomly assigned to the intervention consented to participate in the study. Clinic team member allocation (expressed as a proportion of a full-time position or full-time equivalent [FTE]) and panel size (number of patients) are summarized in Appendix 1, available at www.cmajopen.ca/content/7/2/E371/suppl/DC1.

Clinic teams were randomly assigned 1:1 to the control or intervention group by a statistician external to the project, using a computer-generated random sequence, with concealed allocation. Randomization was stratified by clinic panel size, with 3 strata of 8 clinics each: panel size of 2754 patients or fewer, panel size from 2755 to 6576 patients and panel size of 6577 patients or more. There were a few clinics with more than 1 nurse; however, clustering was minimal. Simple randomization was therefore done, and adjustment for minimal clustering was dealt with in the analysis according to Shultz and colleagues. ${ }^{22}$ Clinics were allocated to intervention or control, 12 clinics to each arm (see the CONSORT flow chart in Figure 2, and Appendix 1).22 The unit of analysis for the randomized controlled trial was the nurse.

\section{Primary quantitative outcome}

The primary quantitative outcome measure was the number of visits conducted by the nurse in which obesity assessment and management was recorded as a significant focus of the visit, as a proportion of their total number of individual patient visits (total clinical activity) for each quarter. This proportion is expressed as a rate ratio. All adult patient visits were eligible and included. If a patient had repeat visits, each visit was eligible and included. Nurses often work part time, so the number of visits was adjusted for their proportion of full-time work (FTE). Expression as a rate ratio takes into account the fact that total clinical activity varies between individual nurses owing to illness and vacation and to their varied mix of clinical duties.

Assessment of the outcome measure was based on analyses of routine administrative data in the PCN, which requires that nurses record the content of each visit for every patient encounter. For example, in a diabetes visit where obesity management was a focus, both diabetes and obesity would be indicated on the form. Encounter forms are periodically audited against clinic notes to ensure accurate capture.

\section{Blinding}

Participants were blinded to the primary outcome measure. Analysts not affiliated with the research team extracted the data from the PCN administrative database and provided deidentified data to the data analysts. Analysts were blinded to group allocation.

\section{Statistical analysis}

Power calculations were based on baseline data and published previously; ${ }^{17}$ for ease of reference the information is also provided here. Power calculations were performed using both simple and cluster randomization where each clinic is considered as a cluster and nurses are clustered within units. The intraclass correlation was estimated to be 0.40 . Power calculations with the 2 approaches were very similar. Given the large numbers of units with only 1 nurse, we opted in favour of a simple randomization approach.

For simple randomization, a power of $77 \%$ was estimated from the sample size of 31 (total number of nurses in the study). ${ }^{17}$ Adjustment for minimal clustering was dealt with in the analysis according to Shultz and colleagues. ${ }^{22}$

Analyses were performed on administrative activity data aggregated quarterly from October 2012 to December 2014. This included up to 12 months of historic data before the intervention, 6 months of intervention data and 9 months of data after the intervention to measure sustainability of impact. Primary analysis was by intention to treat. The baseline differences in the primary outcome measure for the intervention and control groups were compared using the Mann-Whitney test. Generalized estimating equation (GEE) analyses, with a negative binomial distribution, were used to compare the number of weight management clinical encounters between the $5 \mathrm{As} \mathrm{T}$ intervention and control groups. Analyses accounted for minimal clustering effects and for the stratification variable clinic panel size, referring to the number of patients in the clinic. The statistical model is included in Appendix 2, available at www.cmajopen.ca/content/7/2/E371/ suppl/DC1. The GEE was conducted using SAS version 9.4 (SAS Canada). All other quantitative data analyses were conducted using SPSS version 21 (SPSS Inc.). Spearman correlation coefficients between visits per total activity and quarterly 


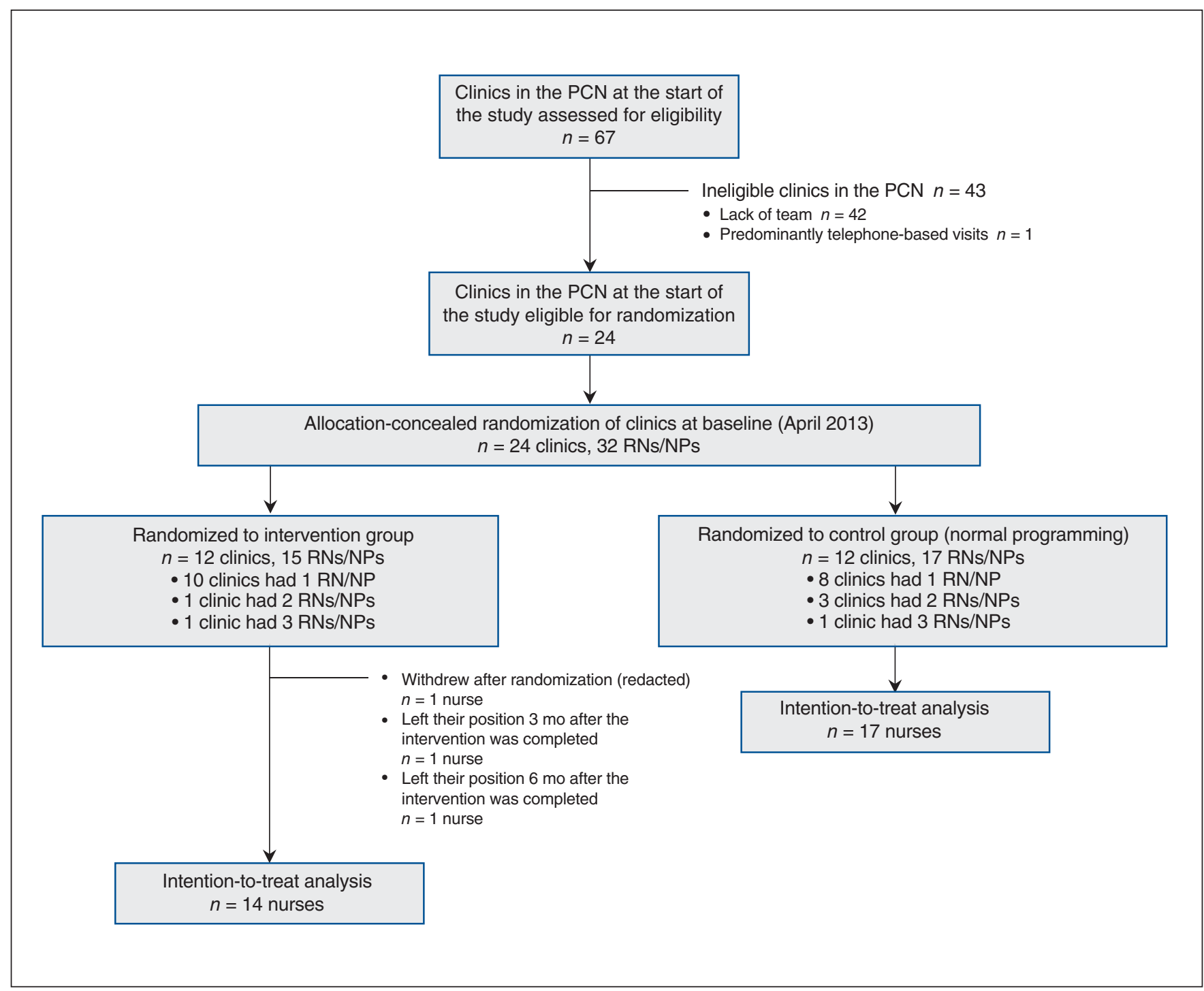

Figure 2: CONSORT diagram. NP = nurse practitioner, $\mathrm{PCN}=$ primary care network, $\mathrm{RN}$ = registered nurse.

time periods for each participant were calculated. All statistical analysis was verified by the Epidemiology Coordinating and Research (EPICORE) Centre, an independent agency (Appendix 3, available at www.cmajopen.ca/content/7/2/ E371/suppl/DC1).

\section{Qualitative and mixed-methods analysis}

A priori, we conducted and reported on a detailed qualitative evaluation to understand the facilitators and barriers affecting the primary outcome measure..$^{23,24}$ Here we report the convergent mixed-methods analysis that assesses the extent to which these barriers and facilitators affected the uptake of the intervention by the nurses and their impact on the quantity of obesity visits.

The qualitative methodology has been published previously. ${ }^{23}$ In brief, the core qualitative data set came from semistructured interviews with the multidisciplinary team providers from the 5AsT intervention arm. Interview questions are provided in Appendix 4, available at www.cmajopen.ca/content/
7/2/E371/suppl/DC1. The interviews were conducted and audio recorded by J.A. (an anthropologist postdoctoral fellow), then transcribed verbatim. Data were augmented by field notes on the 12 intervention sessions, written answers to our exit questionnaire, activity sheets from the interactive wrap-up session at month 6 (end of intervention phase) and the impact discussion session at month 12 (end of passive phase), and logbooks of the research practice facilitators. Coding and analysis procedures are described in detail elsewhere. ${ }^{23}$ The data were analyzed using thematic analysis.

Data mixing was blinded to quantitative results and conducted by an anthropologist (J.A.). Primary interviews and field notes were revisited to categorize each intervention participant by individual and contextual factors affecting their ability to conduct weight management visits. Factors corresponded to themes identified in our prior qualitative analysis: ${ }^{24}$ individual provider confidence or interest; patient and team relationships; clinical environment, role perception, referrals and communication; and views on the intervention's 
value. We compiled detailed descriptions of contextual factors affecting each participant's obesity management visits. Participants were categorized as having barriers and/or positive facilitators to addressing obesity in visits. J.A. and D.C.-S. reviewed these tables for concurrence on categorization. These tables are provided in Appendix 5, available at www. cmajopen.ca/content/7/2/E371/suppl/DC1. Once these assessments were complete, the statistician conducted quantitative Spearman correlations of the outcome measure over time to provide a descriptive view of the data, and these were compared with these individuals' qualitative results (Appendix 6, available at www.cmajopen.ca/content/7/2/ E371/suppl/DC1).

\section{Ethics approval}

The 5AsT study was approved by the University of Alberta Health Research Ethics Board (Pro00036740). Participants gave informed consent before taking part in the study.

\section{Results}

\section{Baseline characteristics}

Table 1 shows the baseline characteristics of the nurses; there were 15 nurses in the intervention clinics and 17 nurses in the control clinics. One nurse from the intervention arm withdrew from the study after randomization and their data were not included. This person was from a clinic with 2 nurses; their colleague stayed in the trial. In the baseline year before the intervention, nurses conducted fewer visits where the focus was obesity than the control nurses (nonsignificant finding; rate ratio $0.84,95 \%$ confidence interval [CI] 0.47-1.49).

\begin{tabular}{|c|c|c|}
\hline Characteristic & $\begin{array}{l}\text { Control group } \\
n=16 \text { nurses }\end{array}$ & $\begin{array}{l}\text { 5AsT } \\
\text { intervention } \\
\text { group } \\
n=15 \text { nurses }\end{array}$ \\
\hline \multicolumn{3}{|l|}{ Demographics } \\
\hline Age, median (IQR), yr & $49.5(17)$ & $44.0(21)$ \\
\hline $\begin{array}{l}\text { No. of clinic patients in } \\
\text { October } 2013 \text {, } \\
\text { median (IQR) }\end{array}$ & 7141 (10 317) & $5976(6595)$ \\
\hline $\begin{array}{l}\text { Full-time equivalent } \\
\text { employment, } \\
\text { median (IQR) }\end{array}$ & $0.90(0.40)$ & $0.83(0.50)$ \\
\hline \multicolumn{3}{|l|}{$\begin{array}{l}\text { Obesity management } \\
\text { encounters per total clinical } \\
\text { activity, } \%\end{array}$} \\
\hline Mean \pm SD & $4.54 \pm 3.07$ & $3.66 \pm 4.31$ \\
\hline Median & 3.90 & 1.90 \\
\hline Lower quartile & 2.40 & 0.20 \\
\hline Upper quartile & 7.10 & 8.20 \\
\hline
\end{tabular}

\section{Impact of the intervention on the primary outcome}

Compared with the control group, the intervention group had a nonstatistically significant $30 \%$ increase in the point estimate of the number of obesity visits conducted over the 6-month intervention (rate ratio $1.30,95 \%$ CI $0.83-2.03$ ). The point estimate over the 9-month sustainability phase showed a $38 \%$ increase, again not statistically significant (rate ratio $1.38,95 \%$ CI $0.87-2.19$ ) (Figure 3). Table 2 provides rate ratio estimates with $95 \%$ CIs. Table 3 provides summary statistics on visits with obesity management as a percentage of total clinical activity.

With regard to individual nurses there was wide variation in visits focusing on obesity. Table 4 summarizes the mixedmethods analysis of the individual providers' barriers and facilitators to change their practice, and whether the qualitative results were concordant with the individual trends in their quantitative individual results of the Spearman correlation. More detailed supplemental data are provided in Appendix 5 and Appendix 6. The observed clinical variability in practice change drove the broad CIs in the main results, and this variability was largely explained by the qualitative results detailed in Appendix 5.

\section{Interpretation}

We found wide variability in the impact of the 5AsT intervention on the number of nurse visits for obesity among the different participants. Compared with the control group, the intervention group had nonstatistically significant $30 \%$ and $38 \%$ increases in the point estimate of the number of visits conducted over the 6-month intervention and the 9-month sustainability phase, respectively. There was wide clinical variability between individual providers. Importantly, the mixed-methods analysis shed light on the variability in provider response to the intervention by demonstrating the role of individual nurses' barriers and facilitators. Thus, individual provider confidence, their personal views of obesity management, role identity and both their interprofessional relationships and patient relationships within their practice were found to affect individuals' uptake of the intervention. For example, Provider 19, who admitted a lack of confidence in discussing obesity, discomfort about the intervention and perceived minimal interest in obesity management at their clinic, never performed a clinical encounter for obesity. In contrast, Provider 11 attended all of the intervention and developed significant comfort with addressing obesity. This provider indicated that before the intervention they were not addressing weight as often as they should, and their individual results showed a significant change in practice.

Our observation of wide variability in uptake of the $5 \mathrm{AsT}$ intervention is consistent with previous observations regarding behaviour change in health practitioners. A recent Cochrane review highlighted the paucity of trials in the area. ${ }^{6}$ Moore and colleagues' ambitious trial in 44 primary care practices in England was hampered by variable uptake by practitioners, and as a result the researchers were unable to draw conclusions about the effectiveness of the intervention for patient weight loss. ${ }^{25}$ They did demonstrate that practitioners 


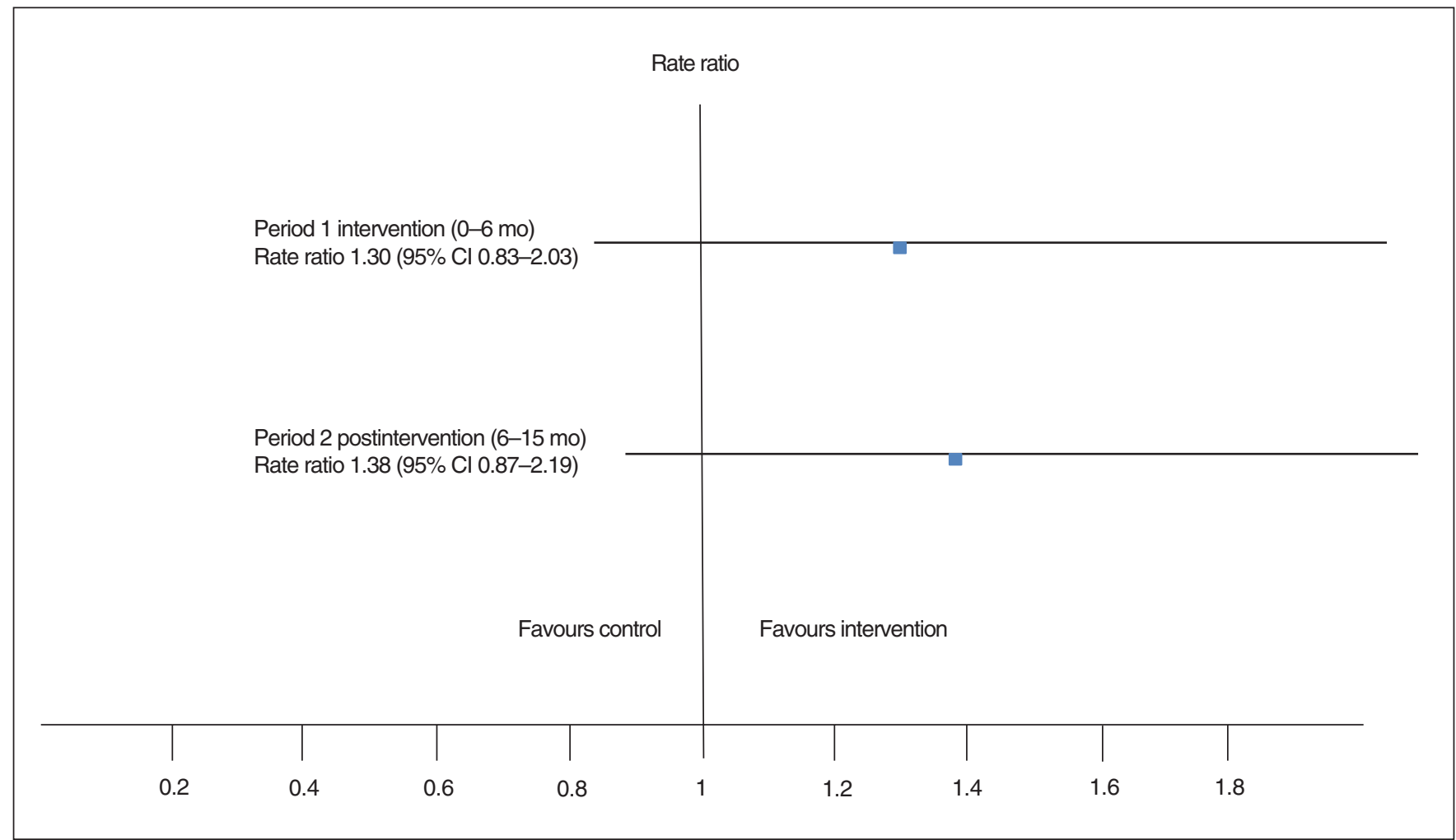

Figure 3: Effect of the intervention on the number of visits per full-time equivalent conducted over the 6-month intervention period and the 9-month sustainability period. $\mathrm{Cl}=$ confidence interval.

\begin{tabular}{|c|c|}
\hline \multicolumn{2}{|c|}{$\begin{array}{l}\text { Table 2: Incidence rate ratio estimates of obesity visits } \\
\text { conducted by nurses }\end{array}$} \\
\hline Parameter & Rate ratio $(95 \% \mathrm{Cl})$ \\
\hline \multicolumn{2}{|l|}{ Group at baseline } \\
\hline Control & Ref. \\
\hline 5AsT intervention & $0.84(0.47-1.49)$ \\
\hline \multicolumn{2}{|l|}{ Time period } \\
\hline Baseline (Q1-Q4) & Ref. \\
\hline Intervention (Q5-Q6) & $0.95(0.78-1.16)$ \\
\hline Postintervention (Q7-Q9) & $0.79(0.6-1.05)$ \\
\hline \multicolumn{2}{|l|}{ Group*time period interaction } \\
\hline After 6-mo intervention & $1.30(0.83-2.03)$ \\
\hline After 9-mo sustainability phase & $1.38(0.87-2.19)$ \\
\hline Total activity* & $1.0005(1.0002-1.0007)$ \\
\hline \multicolumn{2}{|l|}{ Clinic panel size, no. of patients } \\
\hline$\leq 2754$ & Ref. \\
\hline $2755-6576$ & $0.47(0.23-0.99)$ \\
\hline$\geq 6577$ & $0.56(0.28-1.14)$ \\
\hline \multicolumn{2}{|c|}{$\begin{array}{l}\text { Note: Analysis accounted for minimal clustering effects and for the stratification } \\
\text { variable clinic panel size; see Appendix } 3 \text { for the model. Correlation structure: } \\
\text { autoregressive of order } 1 \text {. Inference is based on robust standard error. See } \\
\text { Appendix } 1 \text { for details of the statistical model. Cl = confidence interval, } Q= \\
\text { quarter of year, Ref. = referent. } \\
\text { Quarterly total of all clinical encounters. }\end{array}$} \\
\hline
\end{tabular}

\begin{tabular}{|lcc|}
\hline $\begin{array}{l}\text { Table 3: Summary statistics of obesity management visits } \\
\text { per total activity }\end{array}$ & $\begin{array}{c}\text { Control group } \\
\text { median \% (IQR) }\end{array}$ & $\begin{array}{c}\text { Intervention } \\
\text { group } \\
\text { median \% (IQR) }\end{array}$ \\
\hline Time period & $3.77(2.61-6.33)$ & $2.08(0.48-7.98)$ \\
\hline Baseline (12 mo) & $2.49(1.30-5.59)$ & $1.54(0.63-8.34)$ \\
\hline Intervention (6 mo) & $2.61(1.10-3.92)$ & $3.91(0.64-8.79)$ \\
\hline Postintervention (9 mo) & & \\
\hline Note: IQR = interquartile range. & & \\
\hline
\end{tabular}

increased their self-reported knowledge and inclusion of learned strategies in practice. Davis Martin and colleagues conducted a randomized trial of physician training and support of a multidisciplinary team to improve obesity care. ${ }^{26}$ The target population was low-income African-American women in primary care, and weight loss in patients was the outcome. Statistically significant modest weight loss was achieved. Owing to the complex pathophysiology of obesity, weight loss is contested as an outcome measure and may not well reflect provider behaviour change. ${ }^{27}$ These studies provide little insight into the actual determinants of clinician behaviours. Clearly, as in the present study, future research in this area would benefit from applying mixed methods in an effort to explain why and how a given intervention may or may not have led to changes in provider behaviours. 


\begin{tabular}{|c|c|c|c|}
\hline $\begin{array}{l}\text { Intervention } \\
\text { provider ID }\end{array}$ & $\begin{array}{c}\text { No. of } \\
\text { sessions } \\
\text { attended } \\
\text { (out of 12) }\end{array}$ & $\begin{array}{l}\text { Barriers to or facilitators of } \\
\text { uptake of the intervention } \\
\text { based on qualitative results }\end{array}$ & $\begin{array}{c}\text { Concordance between } \\
\text { qualitative prediction of } \\
\text { changing practice and the } \\
\text { individual trends in } \\
\text { quantitative outcome }\end{array}$ \\
\hline 26 & 10 & Major barriers & Concordant \\
\hline 9 & 6 & Major barriers & Concordant \\
\hline 7 & 11 & Major barriers & Concordant \\
\hline 19 & 8 & Major barriers & Concordant \\
\hline 8 & 12 & Barriers and facilitators & Concordant \\
\hline 29 & 10 & Barriers and facilitators & Concordant \\
\hline 3 & 7 & Barriers and facilitators & Concordant \\
\hline 11 & 12 & Facilitators & Concordant \\
\hline 22 & 9 & Facilitators & Concordant \\
\hline 28 & 12 & Facilitators & Concordant \\
\hline 27 & 11 & Facilitators & Concordant \\
\hline 4 & 6 & Facilitators & Discordant \\
\hline 21 & 10 & Facilitators & Discordant \\
\hline 20 & 12 & Facilitators & Concordant \\
\hline
\end{tabular}

\section{Limitations}

We recognize a number of limitations to our work. Our qualitative results demonstrated multifaceted clinically meaningful impacts on providers and teams to improve obesity management in primary care. ${ }^{23}$ However, we did not observe statistically significant increases in clinical activity between the intervention and control arms in this quantitative analysis. This may be due to the greater than anticipated observed variation in nurses' clinical activity and the small sample size, which led to very large confidence intervals around the point estimates. This variability was largely explained by the qualitative findings of differences in individual nurses' personal facilitators and barriers to change as shown in the mixed-methods results. While the PCN structure is unique to Alberta and may not be generalizable to other contexts, the personal and contextual factors affecting the ability of individual nurses to change their obesity practice may provide transferable insights.

\section{Conclusion}

Despite co-creation of the intervention by the participants, the study did not demonstrate a statistically significant increase in the number of primary care nurse visits that focused on obesity. Although we observed an increase in the point estimate, this difference failed to reach statistical significance because of wide variability in uptake among individual participants. Nevertheless, the mixed-methods analysis used in this study does provide important insights into the facilitators and challenges that health practitioners encounter in changing practice behaviours in the context of obesity management.

\section{References}

1. Finucane MM, Stevens GA, Cowan MJ, et al.; Global Burden of Metabolic Risk Factors of Chronic Diseases Collaborating Group (Body Mass Index). National, regional, and global trends in body-mass index since 1980: systematic analysis of health examination surveys and epidemiological studies with 960 country-years and 9.1 million participants. Lancet 2011; 377:557-67.

2. Global status report on noncommunicable diseases 2010. Geneva: World Health Organization; 2011. Available: http://whqlibdoc.who.int/publications /2011/9789240686458_eng.pdf?ua=1 (accessed 2015 Oct. 5).

3. Dietz WH, Baur LA, Hall K, et al. Management of obesity: improvement of health-care training and systems for prevention and care. Lancet 2015; 385:2521-33.

4. Flodgren G, Deane K, Dickinson HO, et al. Interventions to change the behaviour of health professionals and the organisation of care to promote weight reduction in overweight and obese adults. Cochrane Database Syst Rev 2010;3:CD000984.

5. Katz A, Lambert-Lanning A, Miller A, et al. Delivery of preventive care: the national Canadian Family Physician Cancer and Chronic Disease Prevention Survey. Can Fam Physician 2012;58:e62-9.

6. Flodgren G, Gonçalves-Bradley DC, Summerbell CD. Interventions to change the behaviour of health professionals and the organisation of care to promote weight reduction in children and adults with overweight or obesity. Cochrane Database Syst Rev 2017;11:CD000984.

7. Jay M, Gillespie C, Schlair S, et al. Physicians' use of the 5 As in counseling obese patients: Is the quality of counseling associated with patients' motivation and intention to lose weight? BMC Health Serv Res 2010;10:159.

8. Lau DC, Douketis JD, Morrison KM, et al.; Obesity Canada Clinical Practice Guidelines Expert Panel. 2006 Canadian clinical practice guidelines on the management and prevention of obesity in adults and children [summary]. CMAf 2007;176:S1-13.

9. Brauer P, Gorber SC, Shaw E, et al.; Canadian Task Force on Preventive Health Care. Recommendations for prevention of weight gain and use of behavioural and pharmacologic interventions to manage overweight and obesity in adults in primary care. CMA7 2015;187:184-95.

10. Freedhoff Y, Sharma AM. Best Weight: a practical guide to office-based obesity management. Edmonton: Canadian Obesity Network — Réseau Canadien en obésité; 2010. Available: https://obesitycanada.ca/wp-content/uploads/2018/07/ Best-Weight-Book.pdf (accessed 2015 Oct. 5).

11. Sharma AM, Padwal R. Obesity is a sign - over-eating is a symptom: an aetiological framework for the assessment and management of obesity. Obes Rev 2010;11:362-70. 
12. Schlair SL, Moore S, McMacken M, et al. How to deliver high-quality obesity counseling in primary care using the 5As framework. 7 Clin Outcomes Manag 2012;19:221-9.

13. Vallis M, Piccinini-Vallis H, Sharma AM, et al. Clinical review: modified 5 As minimal intervention for obesity counseling in primary care. Can Fam Physician 2013;59:27-31.

14. Rueda-Clausen CF, Benterud E, Bond T, et al. Effect of implementing the 5As of obesity management framework on provider-patient interactions in primary care. Clin Obes 2014;4:39-44.

15. Jay MR, Gillespie CC, Schlair SL, et al. The impact of primary care resident physician training on patient weight loss at 12 months. Obesity (Silver Spring) 2013;21:45-50.

16. Ogunleye A, Osunlana A, Asselin J, et al. The 5 As team intervention: bridging the knowledge gap in obesity management among primary care practitioners [published erratum in BMC Res Notes 2016;9:164]. BMC Res Notes 2015;8:810.

17. Campbell-Scherer DL, Asselin J, Osunlana AM, et al. Implementation and evaluation of the $5 \mathrm{As}$ framework of obesity management in primary care: design of the 5 As Team (5AsT) randomized control trial. Implement Sci 2014;9:78.

18. Evolving Primary Care Networks in Alberta: a companion document to the PCN evolution vision and framework (December 2013) of the Primary Care Alliance. Edmonton: Alberta Health; 2013. Available: http://pcnevolution. pcnpmo.ca/SiteCollectionDocuments/PCNe\%20Overview/PCN\%20Evolution \%20Companion \%20Doc.pdf (accessed 2015 Nov. 23).

19. Osunlana AM, Asselin J, Anderson R, et al. 5As Team obesity intervention in primary care: development and evaluation of shared decision-making weight management tools. Clin Obes 2015;5:219-25.

20. Michie S, Johnston M, Abraham C, et al. "Psychological Theory" Group. Making psychological theory useful for implementing evidence based practice: a consensus approach. Qual Saf Health Care 2005;14:26-33.

21. 5As Team: improving obesity prevention and management in primary care. Edmonton: Obesity Canada. Available: https://obesitycanada.ca/5as-team/ (accessed 2019 Feb. 3).

22. Schulz KF, Altman DG, Moher D; CONSORT Group. CONSORT 2010 statement: updated guidelines for reporting parallel group randomised trials. BM7 2010;340:c332.

23. Asselin J, Salami E, Osunlana A, et al. Qualitative study of the impacts of the 5 As Team study to change clinical practice in primary care obesity management. CMA7 Open 2017;5:E322-9.

24. Asselin J, Osunlana AM, Ogunleye AA, et al. Challenges in interdisciplinary weight management in primary care: lessons learned from the 5 As Team study. Clin Obes 2016;6:124-32.

25. Moore H, Summerbell CD, Greenwood DC, et al. Improving management of obesity in primary care: cluster randomised trial. BM7 2003;327:1085.

26. Davis Martin P, Rhode PC, Dutton GR, et al. A primary care weight management intervention for low-income African-American women. Obesity (Silver Spring) 2006;14:1412-20.

27. Sturgiss E, Jay M, Campbell-Scherer DL, et al. Challenging assumptions in obesity research. BM7 2017;359:j5303.

Affiliations: Department of Family Medicine (Campbell-Scherer, Cave) and Alberta Diabetes Institute (Campbell-Scherer, Johnson, Sharma), University of Alberta, Edmonton, Alta.; Department of Anthropology (Asselin), University of Lethbridge, Lethbridge, Alta.; Department of
Medicine (Osunlana, Ogunleye, Sharma), Division of Endocrinology, University of Alberta; Edmonton Southside Primary Care Network (Fielding, Anderson); School of Public Health (Johnson), University of Alberta, Edmonton, Alta.

Contributors: Denise Campbell-Scherer and Arya Sharma, supported by Jeffrey Johnson and Sheri Fielding, conceived of the study, wrote the grant and supervised the project. Denise Campbell-Scherer, Jodie Asselin and Adedayo Osunlana wrote the application for ethics approval and the protocol. Denise Campbell-Scherer, Jodie Asselin, Adedayo Osunlana, Robin Anderson, Ayodele Ogunleye and Andrew Cave conducted the intervention and evaluation, with clinical operations overseen by Sheri Fielding. Jodie Asselin led the qualitative data collection, supported by Denise Campbell-Scherer, Adedayo Osunlana, Ayodele Ogunleye and Andrew Cave. All authors participated in regular data analysis and review meetings. Robin Anderson, Ayodele Ogunleye and Denise CampbellScherer oversaw the quantitative data collection. Denise CampbellScherer and Ayodele Ogunleye oversaw the statistical analysis. Denise Campbell-Scherer and Jodie Asselin wrote the manuscript. All authors revised the manuscript for important intellectual content, approved the final version to be published and agreed to be accountable for all aspects of the work.

Funding: The 5AsT study is funded by Alberta Innovates - Health Solutions, with significant in-kind support from the Edmonton Southside Primary Care Network. The researchers are independent of the study funder. The funder had no access to study data, no involvement in the design or execution of the study, no involvement in analysis and no role in the decision to publish.

Acknowledgements: The authors thank their community partner, the Edmonton South Side Primary Care Network, for their engagement and work on this project. The authors also thank the front-line health care providers, administrative staff, management and patients for their support of the 5 As Team project. Statistical support was provided by Imran Hassan, biostatistician for EPICORE. Christian Rueda-Clausen assisted in writing the grant.

Prior research presentations: Oral presentations were given at the North American Primary Care Research Group (NAPCRG) Annual Meeting in Cancun, Mexico, on Oct. 26-29, 2015, and at the International Congress on Obesity 2016 in Vancouver on May 4, 2016.

Guarantors: Statistical analyses have been verified by EPICORE, an independent agency. The authors affirm that this manuscript is an honest, accurate, and transparent account of the study being reported; that no important aspects of the study have been omitted; and that any discrepancies from the study as planned and registered have been explained.

Supplemental information: For reviewer comments and the original submission of this manuscript, please see www.cmajopen.ca/content/7/2/ E371/suppl/DC1. 